\title{
APLICAÇÃO DO POSTULADO PÓS-KEYNESIANO NO ESTADO DO RIO DE JANEIRO ATRAVÉS DE UMA ANÁLISE DE CLUSTER
}

\section{APPLICATION OF THE POST-KEYNESIAN POSTULATE IN THE STATE OF RIO DE JANEIRO THROUGH A CLUSTER ANALYSIS}

\author{
Daniel Ramos Meotte* E-mail: daniel meotte@hotmail.com \\ Maécio Pinto Baptista* E-mail: maeciobaptista@gmail.com \\ Rafael da Silva Sanches* E-mail: rafael7sanches@yahoo.com.br \\ Alcimar das Chagas Ribeiro* professoralcimar@gmail.com \\ *Universidade Estadual do Norte Fluminense Darcy Ribeiro (UENF), Campos dos Goytacazes - RJ
}

Resumo: A discussão sobre o papel da moeda na economia e no desenvolvimento regional, só cresce ao longo dos anos. Na literatura muitos autores defendem que a moeda é neutra, mas outros autores baseados na teoria pós-keynesiana, consideram que a não neutralidade da moeda pode ajudar a aumentar ou diminuir a desigualdade no desenvolvimento regional, ou seja, moeda é endógena ao sistema econômico. Portanto, seguindo essa linha, o atual artigo tem como objetivo verificar o grau de preferência pela liquidez dos bancos e do público nos clusters de municípios presentes no estado do Rio de Janeiro. A partir de uma análise multivariada de cluster e baseados na teoria pós-keynesiana, foi possível observar a disparidade no grau de preferência entre os clusters. Em geral, quanto mais desenvolvido é o cluster de municípios, menor é o grau de preferência pela liquidez, seja dos bancos, seja do público, ficando evidente que o centro das regiões tende a concentrar a disponibilidade de crédito dos bancos e da utilização desses créditos por parte do público.

Palavras-chave: Análise de cluster. Preferência pela liquidez. Desenvolvimento regional.

Abstract: The debate about the role of money in the local economy and development has only been growing over the years. In the literature, many authors argue that currency is neutral; on the other hand, many others, based on the post-Keynesian theory, consider that the non-neutrality of the currency can help increase or decrease inequality in local development, meaning that currency would be endogenous to the economic system. Therefore, in this line of thought, this article aims to verify the degree of liquidity preference of banks and people in the clusters of cities located in the state of Rio de Janeiro. From a multivariate cluster analysis and based on the post-Keynesian theory, it was possible to observe the discrepancy in the degree of preference among clusters. Generally, the more developed the cluster of cities is, the lower the degree of liquidity preference, either from the banks or from the people, making it clear that the center of the regions tends to concentrate the banks' credit availability and the use of these credits by the people.

Keywords: Cluster Analysis. Preference for liquidity. Regional development.

\section{INTRODUÇÃO}

Há algum tempo tem se discutido sobre o verdadeiro papel da moeda no processo de desenvolvimento de uma região. A literatura clássica aborda a moeda como neutra, baseando-se em indicadores macroeconômicos, tais como: poupança, 
emprego e renda, PIB, não permitindo um estudo mais descentralizado, dificultando o entendimento da real trajetória econômica das regiões componentes. Todavia, os autores mais atuais têm apresentado trabalhos que abordam uma teoria diferente da clássica para a análise regional. Autores tais como Amado (1998), Freitas e Paula (2010) e Ribeiro e Marouvo (2016) vem utilizando as principais bases da teoria póskeynesiana sobre a relação entre moeda e produção. Estes e outros autores passaram a considerar a não neutralidade da moeda, já que as variáveis monetárias podem ajudar a aumentar ou diminuir a desigualdade de desenvolvimento entre as regiões de um determinado país. A moeda é endógena ao sistema econômico, é disponibilizada através do crédito bancário, o que transforma os bancos em agentes econômicos, não apenas financeiros.

Diante deste quadro, o objetivo deste artigo é o de verificar o grau de preferência pela liquidez dos bancos e do público nos clusters de municípios presentes no estado do Rio de Janeiro. Para isso, primeiramente, é necessário agrupar todos os municípios do estado de acordo com as similaridades do nível de desenvolvimento. Isso é realizado com o auxílio da análise multivariada de cluster. Posteriormente é realizada a análise dos clusters, com um enfoque Pós-Keynesiano, o qual define que regiões menos desenvolvidas possuem uma maior preferência pela liquidez, em virtude de maior incerteza econômica.

\section{REFERENCIAL TEÓRICO}

\subsection{Moeda Endógena}

Segundo Ribeiro e Marouvo (2016), os trabalhos de análise da economia regional se baseiam em modelos que adotam a moeda como neutra ou como se tivesse uma perfeita mobilidade entre regiões. Neste sentido, os fluxos monetários intrarregionais são vistos como simples reflexos dos níveis de desenvolvimento das regiões e das instituições. Tais trabalhos consideram a moeda e os fluxos financeiros como um resultado das diferenças regionais e não como um fator influenciador de tais diferenças.

Amado (1998) ressalta que a importância dada à moeda tem se modificado através da história do pensamento econômico. Entretanto, a autora destaca que a teoria clássica ainda trata a moeda como um elemento sem importância. O tratamento 
atribuído à moeda foi sempre o de um elemento facilitador das trocas. Isto se reduz apenas aos efeitos transitórios de curto prazo, causados pelas fricções características desses períodos e não por nenhum elemento intrínseco ao processo econômico em economias monetárias de produção.

Todavia, a não neutralidade da moeda deve ser considerada, dado que as variáveis monetárias contribuem para a ampliação ou diminuição das diferenças regionais de um país (RIBEIRO; MAROUVO, 2016). A teoria pós-Keynesiana admite que diferenças entre rendas regionais possuam fatores estruturais como causa e que as variáveis monetárias mantêm ou ampliam tais desigualdades. Neste sentido, tal teoria considera a moeda como endógena ao sistema econômico, sendo inserida na economia por meio do crédito bancário. Logo, os bancos se tornam agentes ativos em sua alocação de recursos com a capacidade de criar dinheiro novo através da moedacrédito (FREITAS; PAULA, 2010; RIBEIRO; MAROUVO, 2016).

\subsection{Preferência pela Liquidez}

A moeda é o ativo líquido por excelência e possui as propriedades essenciais de apresentar elasticidades de produção e substituição iguais à zero. Ou seja, não se pode aumentar a produção de moeda rapidamente e tampouco se pode substituí-la, pois a moeda é, em última instância, depositária do poder de compra (BRAGA; RAIMUNDINI; BIANCHI, 2010).

Segundo Vercelli (2016), Keynes define liquidez como "capacidade de realização imediata sem perda". Esta definição sugere imediatamente que o grau de liquidez de um ativo depende de duas variáveis básicas: os custos de transação esperados em caso de liquidação e o horizonte temporal dentro do qual a liquidação precisa ser realizada.

Para Lopez e Rossetti (1998), a liquidez é um conceito intrínseco a qualquer ativo e depende: da facilidade com que pode ser comprado ou vendido, dos custos de transação, e do grau de estabilidade e previsibilidade de seu valor. Um imóvel tem uma liquidez menor em relação à moeda, pois não apresenta certa facilidade em transacioná-lo além de apresentar custos de transação e corretagem e maiores oscilações em seu valor. É importante observar também que dinheiro e liquidez não 
são sinônimos. Ambos os conceitos são relacionados, mas em certas circunstâncias é importante distingui-los (ESTEBAN, 2014).

$\mathrm{Na}$ literatura existem duas teorias da preferência pela liquidez bem estruturadas. Uma delas é a de Tobin (1958) que diz que os agentes trocarão a liquidez por investimentos em títulos do governo somente nos casos em que as expectativas futuras sobre o retorno e risco associados ao investimento forem boas, isto é, altos retornos e baixos riscos. Já a teoria de Keynes (1964) explica a razão pela qual os indivíduos guardam dinheiro em papel. A teoria afirma que as pessoas preferem a liquidez a outros investimentos por três razões específicas: transação, precaução e especulação (NAKAMURA, 2004).

\subsection{Bancos e Desenvolvimento Regional no Brasil}

A partir do ano de 1994 o setor bancário brasileiro passou por uma reestruturação. Houve uma redução do número de instituições financeiras regionais, tais como bancos estaduais e grupos privados de médio porte, cujo foco principal de atuação era seus estados e regiões. Com isto, as regiões menos desenvolvidas foram submetidas às decisões estratégicas de grandes grupos bancários nacionais e internacionais, localizando-se em sua maioria na cidade de São Paulo (FREITAS; PAULA, 2010).

Ainda segundo Freitas e Paula (2010), ocorreu também um processo de concentração regional dos centros de decisão dos bancos que atuam no Brasil, juntamente com a formação de grandes conglomerados bancários na cidade de São Paulo. De acordo com o Banco Central, 40\% das instituições financeiras no Brasil se localizavam nos estados de São Paulo e Rio de Janeiro em 2007.

Outras regiões do país, principalmente as Norte e Nordeste, regiões mais pobres que a Sul e Sudeste, foram varridas do mapa bancário nacional. Estas regiões mais pobres e menos povoadas só atraíram o interesse do sistema financeiro diante da possibilidade normativa de novas formas de topologia bancária, tais como os correspondentes bancários, as lojas de crédito e o banco postal (SCHERMA; KAHIL, 2011).

Tais dados confirmam a teoria abordada por economistas pós-Keynesianos, de que um sistema bancário baseado em grandes bancos produz uma tendência à 
concentração bancária (FREITAS; PAULA, 2010). Essa concentração ocorre nas regiões centrais, pois são mais atraentes à alocação de recursos. Este fato acaba por perpetuar as desigualdades regionais, aonde apenas esforços governamentais serão capazes de mudar tal cenário (NOGUEIRA; CROCCO E SANTOS, 2010).

Scherma e Kahil (2011) afirmam que, em 2007, foram concedidos $R \$ 712,68$ bilhões de reais em crédito para as regiões Sul e Sudeste, enquanto foram coletados $\mathrm{R} \$ 618,57$ bilhões de reais em depósitos. Tais regiões foram ganhadoras de capital. Já a região Nordeste recebeu $R \$ 51,164$ bilhões de reais no mesmo ano, enquanto sua captação em depósitos foi de $R \$ 73,23$ bilhões de reais, confirmando que tal região "perdeu" crédito.

Estes fatos apresentados mostram que regiões menos desenvolvidas com bancos em estágios menos desenvolvidos possuem menor capacidade de criação de crédito. Bancos e tomadores de empréstimos também apresentam comportamento diferenciado dependendo da localização em regiões periféricas ou centrais, onde o risco e a disposição em emprestar ou pegar emprestado variam, refletindo sobre os níveis de preferência pela liquidez e aversão ao risco dos agentes (FREITAS; PAULA, 2010).

\section{PROCEDIMENTOS METODOLÓGICOS}

\subsection{Objeto de Estudo}

O objeto de estudo desta pesquisa são todos os 92 municípios do estado do Rio de Janeiro, escolhidos pelo fato de pertencerem ao estado no qual pertence a instituição de ensino dos pesquisadores. Com o número total dos municípios do estado, pode-se contribuir com análises financeiras, em face das teorias póskeynesianas, no sentido de como os municípios do estado se comportam com a riqueza gerada em seu território.

\subsection{Procedimentos de Coleta de dados}

O presente trabalho se utiliza das características socioeconômicas e das variáveis financeiras dos municípios do estado do Rio de Janeiro. Os dados referentes às características socioeconômicas dos 92 municípios do estado do Rio de Janeiro, 
que são empregados no modelo de agrupamento (análise de clusters), são expressos por indicadores de desenvolvimento humano, demografia, educação, mercado de trabalho, população, habitação e nível de renda. Todos esses dados foram extraídos do Atlas do Desenvolvimento Humano no Brasil (2013) para o Censo de 2010 e são apresentados no Quadro 1.

Quadro 1 - Variáveis socioeconômicas

\begin{tabular}{|c|c|c|c|}
\hline SIGLA & VARIÁVEL & FORMAÇÃO & REPRESENTAÇÃO \\
\hline idhm_e & $\begin{array}{l}\text { Índice } \\
\text { Desenvolvimento } \\
\text { Humano - Dimensão } \\
\text { Educação }\end{array}$ & $\begin{array}{l}\text { Média geométrica do } \\
\text { subíndice de frequência de } \\
\text { crianças e jovens à escola, } \\
\text { com peso de } 2 / 3 \text {, e do } \\
\text { subíndice de escolaridade } \\
\text { da população adulta, com } \\
\text { peso de } 1 / 3 \text {. }\end{array}$ & Educação \\
\hline idhm_I & $\begin{array}{l}\text { Índice } \\
\text { Desenvolvimento } \\
\text { Humano - De } \\
\text { Longevidade }\end{array}$ & $\begin{array}{l}\text { É obtido com base no } \\
\text { indicador Esperança }= \\
\text { [(valor observado do } \\
\text { indicador) - (valor mínimo)] / } \\
\text { [(valor máximo) - (valor } \\
\text { mínimo)], onde os valores } \\
\text { mínimo e máximo são } 25 \text { e } \\
85 \text { anos, respectivamente. }\end{array}$ & Longevidade \\
\hline idhm_r & $\begin{array}{l}\text { Índice } \\
\text { Desenvolvimento } \\
\text { Humano - Dimensão } \\
\text { Renda }\end{array}$ & $\begin{array}{l}\text { [n (valor observado do } \\
\text { indicador) - In (valor } \\
\text { mínimo)] / [In (valor máximo) } \\
\text { - In (valor mínimo)], onde os } \\
\text { valores mínimo e máximo } \\
\text { são } R \$ 8,00 \text { e } R \$ 4.033,00 \\
\text { (a preços de agosto de } \\
2010) \text {. }\end{array}$ & Renda \\
\hline t_lixo & $\begin{array}{l}\text { \% da população em } \\
\text { domicílios com coleta de } \\
\text { lixo }\end{array}$ & $\begin{array}{l}\text { Razão entre a população } \\
\text { que vive em domicílios com } \\
\text { coleta de lixo e a população } \\
\text { total residente em domicílios } \\
\text { particulares permanentes } \\
\text { multiplicada por } 100 \text {. }\end{array}$ & Habitação \\
\hline t_luz & $\begin{array}{l}\text { \% da população em } \\
\text { domicílios com energia } \\
\text { elétrica }\end{array}$ & $\begin{array}{l}\text { Razão entre a população } \\
\text { que vive em domicílios } \\
\text { particulares permanentes } \\
\text { com iluminação elétrica e a } \\
\text { população total residente em } \\
\text { domicílios } \\
\text { permanentes multiculares } \\
\text { por } 100 .\end{array}$ & Habitação \\
\hline t_cc & $\begin{array}{l}\% \text { de empregados com } \\
\text { carteira }-18 \text { anos ou } \\
\text { mais }\end{array}$ & $\begin{array}{l}\text { Razão entre o número de } \\
\text { empregados de } 18 \text { anos ou } \\
\text { mais de idade com carteira } \\
\text { de trabalho assinada e o } \\
\text { número total de pessoas } \\
\text { ocupadas nessa faixa etária } \\
\text { multiplicado por } 100 \text {. }\end{array}$ & Mercado de Trabalho \\
\hline
\end{tabular}


Quadro 1 - Variáveis socioeconômicas

\begin{tabular}{|c|c|c|c|}
\hline SIGLA & VARIÁVEL & FORMAÇÃO & REPRESENTAÇÃO \\
\hline razaodep & Razão de Dependência & $\begin{array}{l}\text { Razão entre o número de } \\
\text { pessoas com } 14 \text { anos ou } \\
\text { menos e de } 65 \text { anos ou mais } \\
\text { de idade (população } \\
\text { dependente) e o número de } \\
\text { pessoas com idade entre } 15 \\
\text { e } 64 \text { anos (população } \\
\text { potencialmente ativa) } \\
\text { multiplicado por } 100 .\end{array}$ & Vulnerabilidade \\
\hline gini & Índice de Gini & $\begin{array}{l}\text { Mede o grau de } \\
\text { desigualdade existente na } \\
\text { distribuição de indivíduos } \\
\text { segundo a renda domiciliar } \\
\text { per capita. Seu valor varia de } \\
0, \text { quando não há } \\
\text { desigualdade (a renda } \\
\text { domiciliar per capita de } \\
\text { todos os indivíduos tem o } \\
\text { mesmo valor), a 1, quando a } \\
\text { desigualdade e máxima } \\
\text { (apenas um indivíduo detém } \\
\text { toda a renda). }\end{array}$ & Renda \\
\hline t_extpob & $\begin{array}{l}\% \text { de } \\
\text { pobres }\end{array}$ & $\begin{array}{l}\text { Proporção dos indivíduos } \\
\text { com renda domiciliar per } \\
\text { capita igual ou inferior a } R \$ \\
70,00 \text { mensais, em real de } \\
\text { agosto de } 2010 \text {. }\end{array}$ & Renda \\
\hline t_serv & $\begin{array}{l}\% \text { dos ocupados no setor } \\
\text { serviços }-18 \text { anos ou } \\
\text { mais }\end{array}$ & $\begin{array}{l}\text { Razão entre o número de } \\
\text { pessoas de } 18 \text { anos ou mais } \\
\text { de idade ocupadas no setor } \\
\text { de serviços e o número total } \\
\text { de pessoas ocupadas nessa } \\
\text { faixa etária multiplicado por } \\
100 \text {. }\end{array}$ & Mercado de Trabalho \\
\hline p_dompp & $\begin{array}{l}\text { População total em } \\
\text { domicílios particulares } \\
\text { permanentes, exceto } \\
\text { com renda nula }\end{array}$ & $\begin{array}{l}\text { Refere-se à população } \\
\text { residente em domicílios } \\
\text { particulares permanentes, } \\
\text { excetuando-se aqueles com } \\
\text { renda nula. População de } \\
\text { referência do Índice de Theil- } \\
\text { L. }\end{array}$ & População \\
\hline t_desoc & $\begin{array}{l}\text { Taxa de desocupação - } \\
10 \text { anos ou mais }\end{array}$ & $\begin{array}{l}\text { Percentual da população } \\
\text { economicamente ativa } \\
\text { (PEA) nessa faixa etária que } \\
\text { estava desocupada, ou seja, } \\
\text { que não estava ocupada na } \\
\text { semana anterior à data do } \\
\text { Censo, mas havia procurado } \\
\text { trabalho ao longo do mês } \\
\text { anterior à data dessa } \\
\text { pesquisa. }\end{array}$ & Mercado de Trabalho \\
\hline
\end{tabular}


Quadro 1 - Variáveis socioeconômicas

\begin{tabular}{|l|l|l|l|}
\hline \multicolumn{1}{|c|}{ SIGLA } & \multicolumn{1}{|c|}{ VARIÁVEL } & \multicolumn{1}{c|}{ FORMAÇÃO } & REPRESENTAÇÃO \\
\hline t_agro & \% dos ocupados no setor & $\begin{array}{l}\text { Razão entre o número de } \\
\text { pessoas de 18 anos ou mais } \\
\text { agropecuário }-18 \text { anos }\end{array}$ & Mercado de Trabalho \\
& ou mais & $\begin{array}{l}\text { agropecuário e o número } \\
\text { total de pessoas ocupadas } \\
\text { nessa faixa etária. }\end{array}$ & \\
& & & \\
\hline
\end{tabular}

Fonte: Elaboração própria

Os dados correspondentes às variáveis financeiras (número de agências bancárias, depósitos à vista, depósitos a prazo e operações de crédito) referentes aos anos de 2007, 2010, 2013 e 2016 foram extraídos da Estatística Bancária (ESTBAN) apresentada pelo Banco Central do Brasil. Essas variáveis são empregadas nas análises que irão servir de base para dimensionar o nível de atividade da economia dos municípios.

\subsection{Procedimentos de Análise de dados}

O procedimento de análise dos dados se divide em duas etapas importantes: a fase de agrupamento dos municípios em clusters, e a fase de análise das variáveis financeiras de cada cluster definido na primeira etapa.

\subsubsection{Fase de agrupamento em clusters}

O modelo de agrupamento (cluster) é um método que busca reunir elementos de dados com base na similaridade entre eles. Ocorre a formação de grupos pelo critério de homogeneidade, ou seja, os elementos mais similares se agrupam entre si, ocorrendo uma heterogeneidade entre os grupos formados. Para isso, utiliza-se de um conjunto de variáveis socioeconômicas como fator explicativo.

Esta ferramenta é utilizada por diversas áreas de estudo, aonde procura-se analisar o surgimento de grupos com características semelhantes. Dentre as principais áreas de estudo que utilizam a análise de cluster estão as relacionadas à medicina, bioquímica e genética molecular, ciências agrícolas e biológicas, ciência da computação, engenharia, dentre outras. 
Existem diversos métodos para se realizar uma análise de cluster. Neste trabalho emprega-se a técnica de cluster não hierárquico (k-means) por centroide. Segundo Doni (2004), este método toma um parâmetro de entrada, k, e divide um conjunto de $\mathrm{n}$ elementos em k grupos. Ou seja, o método permite ao usuário, indicar a quantidade de grupos que se deseja separar os elementos. Neste estudo foi definido o agrupamento em 3 clusters. Para Simões e Furtado (2006), após indicar o número de grupos (ou clusters), o algoritmo calcula os elementos que representam os centros dos clusters. Estes elementos estão na base de dados, e são classificados de acordo com sua homogeneidade. Os elementos são movidos heuristicamente até se ter um equilíbrio estático. Todos esses cálculos foram realizados com o auxílio do software estatístico IBM SPSS Statistics 20.

\subsubsection{Análise das variáveis financeiras}

Para esta análise foram observados alguns conceitos chave tratados por teóricos da concepção pós-keynesiana. Esses conceitos referem-se às relações existentes entre as variáveis financeiras, e que possibilitam análises sobre o desempenho econômico do município.

No cenário financeiro, de acordo com Paula e Freitas (2010), quanto maior for a disponibilidade para empréstimos, maior deverá ser o nível de desempenho econômico. Contudo, isso varia de região para região, ou município para município. Caso a região seja apenas uma captadora de recursos, os depósitos ocorridos nesse local podem ser transferidos e emprestados em outro local. Isso não irá representar um nível maior de desempenho econômico, pelo contrário, irá reduzir o desempenho. Dessa forma, ao encontrar uma relação alta para a variável plb, a preferência pela liquidez dos bancos, é sinal de que aquela região possui vazamento de recursos, ou seja, os depósitos ocorridos nessa região são disponibilizados em outros locais. Em outras palavras, quanto maior o valor para o plb, menor é a disponibilidade dos bancos em conceder créditos (CROCCO et al., 2011).

Segundo Crocco et al. (2011), Missio et al. (2010), e Dow e Fuentes (2006), a preferência pela liquidez do público (plp) influencia as decisões dos bancos de como alocar seus recursos. Quanto maior a preferência pela liquidez do público, maior a demanda por ativos mais líquidos e menor a demanda por crédito de longo prazo. 
Dessa forma, a elevada preferência pela liquidez do público faz com que o bancos mantenham uma parcela maior para sanar possíveis saques sazonais.

O Quadro 2 apresenta os indicadores financeiros discutidos na teoria póskeynesianas e o significado de cada um com relação ao desempenho econômico da região.

Quadro 2 - Indicadores financeiros e relação esperada

\begin{tabular}{|c|c|c|c|}
\hline SIGLA & VARIÁVEL & FORMAÇÃO & SIGNIFICADO \\
\hline plb & $\begin{array}{l}\text { Índice de } \\
\text { preferência pela } \\
\text { liquidez bancária } \\
\text { do município }\end{array}$ & $\begin{array}{l}\text { Depósito à vista totais } \\
\text { operações de crédito }\end{array}$ & $\begin{array}{l}\text { Quanto maior a } \\
\text { preferência pela liquidez } \\
\text { bancária na UF, menor a } \\
\text { oferta de crédito e, por } \\
\text { consequência, menor o } \\
\text { nível de atividade. }\end{array}$ \\
\hline plp & $\begin{array}{lr}\text { Índice } & \text { de } \\
\text { preferência } & \text { pela } \\
\text { liquidez } & \text { do } \\
\text { público } & \end{array}$ & $\begin{array}{l}\text { Depósitos à vista totais / } \\
\text { depósitos totais (depósitos à } \\
\text { vista + depósitos a prazo) }\end{array}$ & $\begin{array}{l}\text { Quanto maior } a \\
\text { preferência pela liquidez } \\
\text { do público, menor a } \\
\text { demanda por crédito. } \\
\text { Assim, haverá reflexo } \\
\text { negativo sobre o nível de } \\
\text { atividade da economia. }\end{array}$ \\
\hline
\end{tabular}

Fonte: Elaboração própria

\section{RESULTADOS}

Esta seção se divide em duas subseções. A primeira apresenta os resultados da análise de clusters e, posteriormente, são exibidos os resultados da análise das variáveis financeiras.

\subsection{Fase de agrupamento em clusters}

Em razão da diversidade das condições socioeconômicas dos municípios e da utilização de um grande número de observações (92 municípios do estado do Rio de Janeiro), na primeira fase deste estudo foi definido o número de clusters como sendo 3. Com isso, com os dados das variáveis socioeconômicas coletados, e com o auxílio do software estatístico IBM SPSS Statistics 20, foram agrupados todos os 92 municípios do estado do Rio de Janeiro em grupos chamados de Centro, Intermediário e Periferia, respeitando a ordem de desempenho socioeconômico, o que, segundo 
Gama et al. (2016), possibilita maior heterogeneidade entre os clusters. Os resultados dessa análise de clusters encontram-se na Tabela 1.

Tabela 1 - Valores, em média, das variáveis utilizadas na análise de agrupamento (3 clusters)

\begin{tabular}{|c|c|c|c|c|c|c|c|c|c|c|c|c|c|}
\hline & $\begin{array}{l}\boldsymbol{\Phi}_{\mid} \\
\underline{\underline{\varepsilon}} \\
\underline{\underline{0}}\end{array}$ & $\begin{array}{l}\overline{\underline{E}} \\
\overline{\underline{\varepsilon}} \\
\underline{\underline{0}}\end{array}$ & $\begin{array}{l}\dot{L} \\
\underline{\varepsilon} \\
\underline{\underline{c}}\end{array}$ & $\underset{\text { I }}{\stackrel{\text { x }}{=}}$ & $\stackrel{\text { N }}{\underline{N}}$ & $\begin{array}{l}0 \\
\text { I } \\
\text { I }\end{array}$ & $\begin{array}{l}\frac{0}{d} \\
\frac{0}{0} \\
\mathbb{N} \\
\mathbb{N}\end{array}$ & 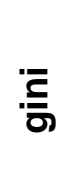 & 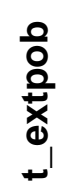 & 胥 & $\begin{array}{l}\text { 응 } \\
\text { 등 } \\
\text { 임 }\end{array}$ & 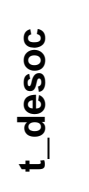 & 잃 \\
\hline Centro & 0,7 & 0,8 & 0,8 & 99,1 & 99,9 & 14,1 & 42,6 & 0,6 & 1,2 & 61,9 & 6.262 .802 & 7,7 & 0,3 \\
\hline Intermediário & 0,6 & 0,8 & 0,7 & 95,3 & 99,9 & 18,2 & 43,3 & 0,4 & 2,5 & 54,4 & 643.958 & 10.2 & 1,1 \\
\hline Periferia & 0,6 & 0,8 & 0,7 & 98,1 & 99,7 & 23,5 & 44,7 & 0,4 & 2,8 & 47,1 & $60.725,5$ & 8,8 & 11 \\
\hline
\end{tabular}

Fonte: Elaboração própria

A Tabela 1 expõe os resultados para a análise de agrupamento para os três clusters. Aquele que na média tem o município mais desenvolvido socioeconomicamente é o cluster denominado de Centro. Este cluster é composto, apenas, pelo município do Rio de Janeiro, como pode ser observado no mapa da figura 1, e apresenta os melhores índices das variáveis que compõem o IDHM educação, longevidade e renda, assim como para os índices das outras variáveis habitação, vulnerabilidade e renda - de controle do modelo de agrupamento. Pode-se observar que, neste cluster, a porcentagem da população que trabalha no setor agrícola é bem baixa; em contrapartida, a porcentagem da população que trabalha no setor de serviços é muito alta. Tal fato está de acordo com a teoria pós-keynesiana, pois os municípios centrais tendem a produzir bens com alta complexidade, principalmente no setor de serviços. Por esses motivos, tal cluster é considerado o mais desenvolvido. 
Figura 1 - Distribuição dos clusters no mapa do estado do Rio de Janeiro

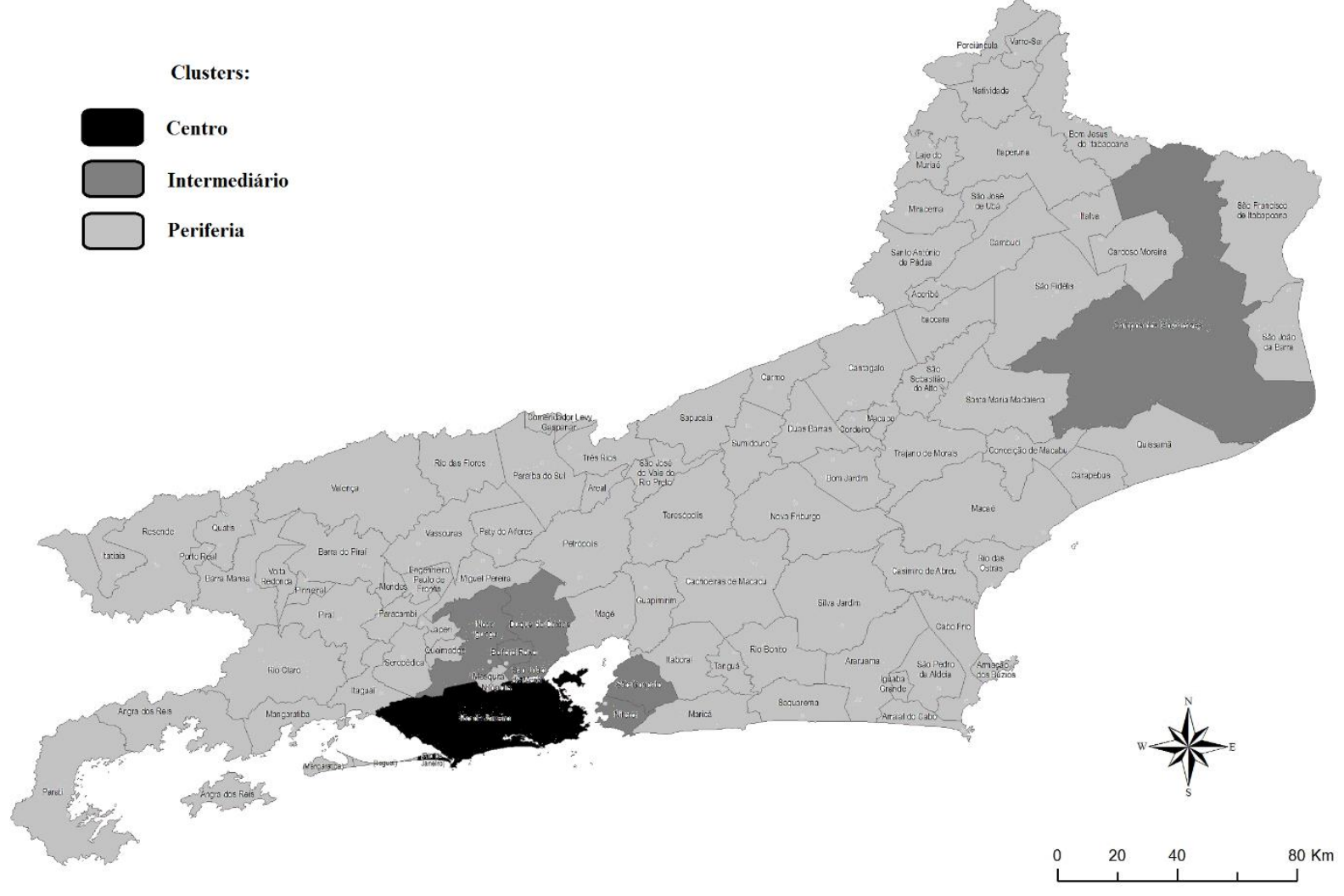

Fonte: Elaboração própria

O segundo cluster, que na média tem os melhores indicadores de desenvolvimento socioeconômico, é denominado de Intermediário. Como é apresentado na Figura 1, este cluster é composto de 7 cidades e é formado em sua maioria por cidades de médio porte, tais como Belford Roxo, Campos dos Goytacazes, Duque de Caxias, Niterói, Nova Iguaçu, São Gonçalo e São João do Meriti. Essas cidades apresentam bons índices de desenvolvimento humano, entretanto, esses índices estão um pouco abaixo dos observados no Centro. Em termos de população, o cluster apresenta níveis elevados de população e elevada participação da população no setor de serviços.

O último cluster, considerado como o de pior desempenho socioeconômico, é o cluster denominado Periferia, composto de 84 municípios, espalhados por todo o interior do estado, como pode ser visto na Figura 1. Esse cluster reúne municípios com baixos níveis de desenvolvimento socioeconômico, dando destaque para o índice de trabalhadores no setor agrícola, pelo baixo número de população e pelo índice de trabalhadores sem carteira de trabalho. Apesar de se situarem no cluster Periferia, os 
índices de variáveis que mensuram o conforto da população - porcentagem da população em domicílios com coleta de lixo (T_lixo) e porcentagem da população em domicílios com energia elétrica (T_luz) - não são baixos, sendo este um fator positivo em todo o estado do Rio de Janeiro.

\subsection{Análise das variáveis financeiras}

A partir da análise de cluster, pode-se agora apresentar os resultados das variáveis financeiras referentes a cada cluster analisado. Na Tabela 2 é apresentado o número de agências dos clusters para os anos descritos. Chama à atenção a disparidade do número de agências entre os clusters. O Centro que conta, apenas, com o município do Rio de Janeiro contém muito mais agências bancárias que os outros dois clusters somados.

\begin{tabular}{lcccc}
\multicolumn{5}{l}{ Tabela 2 - Número de agências bancárias dos clusters } \\
\hline & $\mathbf{2 0 0 7}$ & $\mathbf{2 0 1 0}$ & $\mathbf{2 0 1 3}$ & $\mathbf{2 0 1 6}$ \\
\hline Centro & 1.089 & 1.135 & 1.244 & 1.196 \\
Intermediário & 247 & 275 & 323 & 318 \\
Periferia & 418 & 449 & 536 & 533
\end{tabular}

Fonte: Elaboração própria

A Tabela 3 apresenta a preferência pela liquidez dos bancos para cada cluster analisado. Observa-se que, como foi discutido por Crocco et al. (2011) e Paula e Freitas (2010), os valores são menores para os clusters Centro e Intermediário e maiores para o cluster Periferia, apesar de estarem decrescendo.

\begin{tabular}{lcccc}
\multicolumn{4}{l}{ Tabela 3 - Preferência pela liquidez dos bancos para os clusters } \\
\cline { 1 - 5 } & $\mathbf{2 0 0 7}$ & $\mathbf{2 0 1 0}$ & $\mathbf{2 0 1 3}$ & $\mathbf{2 0 1 6}$ \\
\hline Centro & 0,406 & 0,205 & 0,229 & 0,162 \\
Intermediário & 0,486 & 0,350 & 0,299 & 0,225 \\
Periferia & 0,630 & 0,463 & 0,408 & 0,361
\end{tabular}

Fonte: Elaboração própria

$\mathrm{Na}$ Tabela 4 estão os valores para a preferência pela liquidez do público. Observa-se que, assim como nos valores da preferência pela liquidez dos bancos, os 
valores para os clusters Centro e Intermediário estão próximos, enquanto que os valores para o cluster Periferia estão um pouco acima.

Tabela 4 - Preferência pela liquidez do público para os clusters

\section{$200720102013 \quad 2016$}

\begin{tabular}{lllll}
\hline Centro & 0,434 & 0,188 & 0,149 & 0,077 \\
Intermediário & 0,382 & 0,233 & 0,142 & 0,097 \\
Periferia & 0,445 & 0,317 & 0,265 & 0,160
\end{tabular}

Fonte: Elaboração própria

\section{DISCUSSÕES}

Nesta seção, são discutidos os efeitos da moeda no sentido pós-keynesiano sobre o desempenho econômico de cada cluster de municípios, a partir dos resultados apresentados na seção anterior.

Os resultados da análise de cluster evidenciam a disparidade Norte/Sul ou Centro/Periferia encontrada por outros autores (Carvalho et al., 2012; Gama et al., 2016), que utilizaram metodologias, espaços geográficos (por exemplo, mesorregiões), bem como variáveis e períodos diferentes. Nota-se que todos os municípios do interior do estado, exceto Campos dos Goytacazes, pertencente ao cluster intermediário, que é o maior município em território e em participação econômica do interior, pertencem ao cluster Periferia.

Quanto ao número de agências bancárias, observa-se que todos os clusters tiveram uma redução do número de agências para o ano de 2016, após um período de aumento. Isso pode ser justificado pela crise econômica e política que se instalou no país a partir de 2014. Ao passo que o país se agrava na crise financeira, uma das principais medidas dos bancos, foi a de reduzir agências para reduzir gastos e possibilitar a geração de economia para os mesmos.

As Figuras 2 e 3 mostram a trajetória da preferência pela liquidez dos bancos e do público, respectivamente, nos municípios do estado do Rio de Janeiro. Observase que, ao longo do período, esses dois índices tiveram trajetórias decrescentes. 
Figura 2 - Trajetória da preferência pela liquidez dos bancos dos clusters

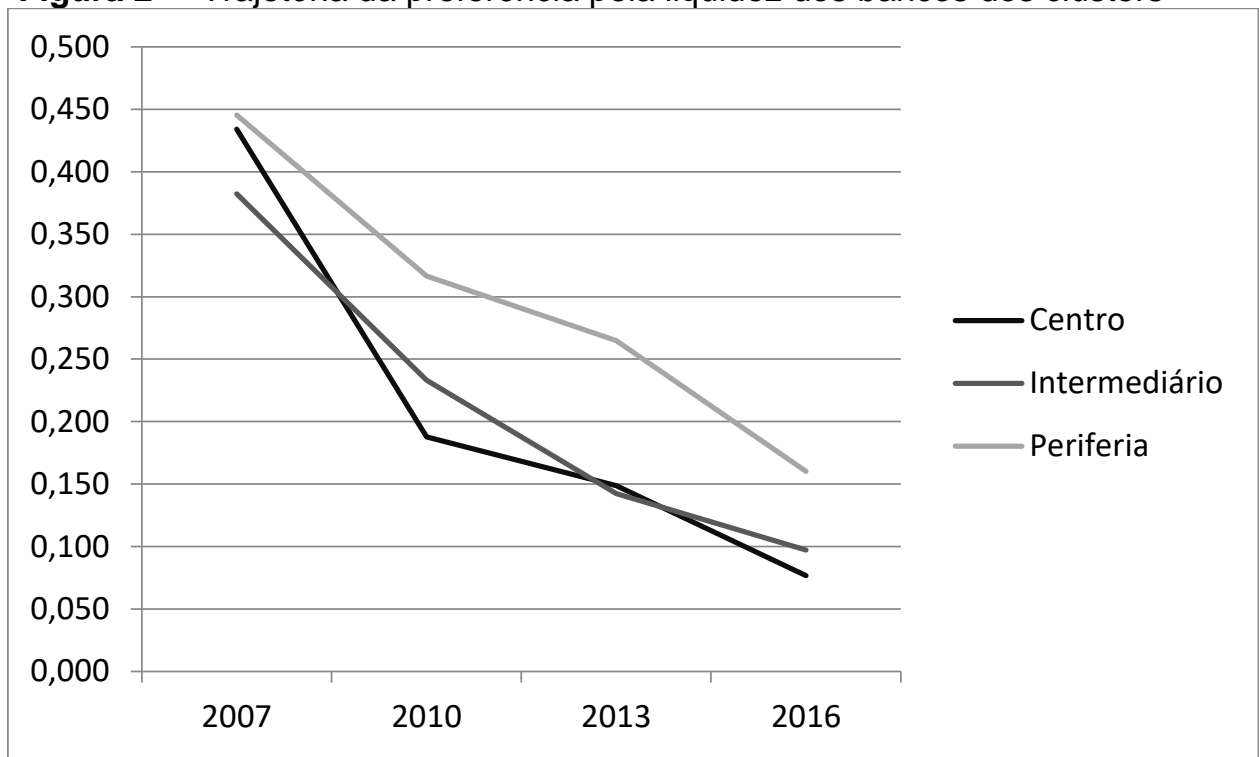

Fonte: Elaboração própria.

Um fato importante a ser destacado na Figura 2 é o comportamento das curvas do plb para os clusters Centro e Periferia. Nota-se que os valores para o cluster Centro são maiores que o cluster Intermediário para os anos de 2007 e 2013. Um indício do que pode ter ocorrido nesses anos é o momento vivido pelo país. Em 2007 o país vivia um constante crescimento da economia, e os bancos procuravam expandir a suas ações para outras cidades com importância no estado, cidades estas pertencentes ao cluster Intermediário. Em 2013, por mais que o país não atravessasse seus melhores dias economicamente, ainda não havia o clima de crise total e a economia, até certo ponto girava bem. Isso mantinha uma política dos bancos de expandirem suas atividades para outras cidades, já que o Centro estava "inchado" com muitas agências. Em contrapartida, verifica-se tanto no ano de 2010, quanto no ano de 2016 um ambiente de instabilidade econômica. Dessa forma, analisando a sequência histórica, nota-se que os bancos, em momentos de incerteza, sempre optam por dirigir suas atividades e seus recursos para os grandes centros, onde as incertezas podem ser minimizadas. 
Figura 3 - Trajetória da preferência pela liquidez do público para os clusters

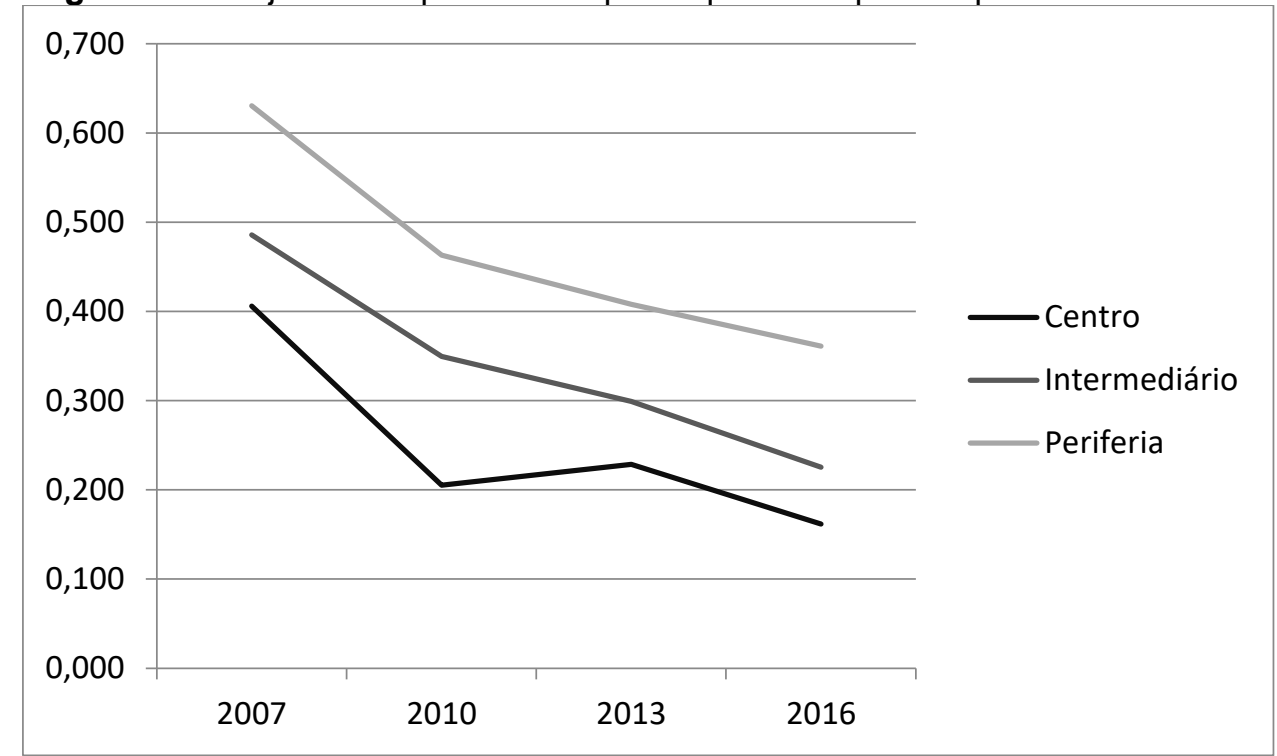

Fonte: Elaboração própria

Nos gráficos 1 e 2 fica evidente o que os teóricos pós-keynesianos dizem a respeito da teoria Centro/Periferia, onde o centro das regiões, aquele local que, seja no quesito geração de riqueza, seja no grau de sofisticação do sistema financeiro, são mais fortes, tende a concentrar a disponibilidade de crédito dos bancos e da utilização desses créditos por parte do público. Na periferia, se produz riqueza, como qualquer cidade, porém a riqueza gerada não se concentra no local e é transferida para os grandes centros.

A teoria aliada aos resultados encontrados induz dizer que Macaé, a cidade forte da indústria do petróleo a nível nacional, com uma geração de riqueza enorme, por exemplo, tem vazamento de recursos, pois faz parte do cluster Periferia. $E$ isso pode ser verificado, por exemplo, pela característica das pessoas que trabalham na indústria do petróleo na cidade. A maioria possui família morando em outros locais do país e só vai à cidade no período de trabalho. Portanto, a recompensa que recebe pelo trabalho gerado não é gasto na cidade, e sim em outra cidade do estado ou do país.

\section{CONCLUSÕES}

O objetivo deste artigo era o de verificar o grau de preferência pela liquidez dos bancos e do público nos clusters de municípios presentes no estado do Rio de Janeiro. 
Para que isso fosse alcançado, primeiramente, se fez necessário agrupar todos os municípios do estado em clusters. Com o auxílio do software estatístico IBM SPSS Statistics 20, definindo como sendo três o número de clusters e como critério o nível de desenvolvimento, os clusters foram formados. O município mais desenvolvido (Rio de Janeiro) ficou no primeiro cluster, denominado Centro, os de desenvolvimento médio (Belford Roxo, Campos dos Goytacazes, Duque de Caxias, Niterói, Nova Iguaçu, São Gonçalo e São João do Meriti) no segundo cluster, denominado Intermediário, e os menos desenvolvidos (todos os outros 84 municípios do estado) no terceiro cluster, denominado Periferia.

Analisando os clusters, a partir dos resultados para os indicadores de preferência pela liquidez dos bancos e público, com enfoque no postulado PósKeynesiano, verificou-se a disparidade no grau de preferência entre os clusters. Em geral, quanto mais desenvolvido é o cluster de municípios, menor é o grau de preferência pela liquidez, seja dos bancos, seja do público. Dessa forma, ficou evidente o que os pós-keynesianos afirmam a respeito da teoria Centro/Periferia, onde o centro das regiões tende a concentrar a disponibilidade de crédito dos bancos e da utilização desses créditos por parte do público.

Uma questão importante foram as análises realizadas acerca da crise financeira que o país vivencia atualmente. Enquanto o país atravessava momentos com economia forte e estável, ou seja, um ambiente com maior certeza do que incerteza, os bancos buscavam expandir suas ações, fazendo com que os índices do plb para os municípios Intermediários ficassem até menor que o município central. Isso significa dizer que as operações de crédito nesses municípios cresceram em comparação com o município do Centro. Porém, ao passo que as incertezas aumentavam, em momentos de crise econômica, por exemplo, os bancos recuavam e voltavam a concentrar suas ações na região central, onde as incertezas tendem a ser menores, inclusive reduzindo o número de agências de forma a cortar gastos e gerar economia. Isso equivale dizer, portanto, que os índices de preferência pela liquidez têm relação direta com o comportamento da economia.

\section{REFERÊNCIAS}

AMADO, A. M.. Moeda, financiamento, sistema financeiro e trajetórias de desenvolvimento regional desigual: a perspectiva pós-Keynesiana. Revista de Economia Política, v. 18, n. 1, p.76-89. São Paulo, 1998. 
ATLAS DO DESENVOLVIMENTO HUMANO NO BRASIL. Programa das nações unidas para o desenvolvimento: material de apoio, perguntas frequentes. 2013.

BANCO CENTRAL DO BRASIL. Estatísticas bancárias dos municípios/ESTBAN.

Disponível em: http://www4.bcb.gov.br/fis/cosif/estban.asp. Acesso em: maio 2017.

BRAGA, L.; RAIMUNDINI, S.; BIANCHI, M. Incerteza, preferência pela liquidez e insuficiência de demanda efetiva: evidências empíricas sobre a crise financeira de 2008.

ConTexto, v. 10, n. 17, p. 79-91, 2010.

CARVALHO, D. M.; PEREIRA, F. A. A.; OLIVEIRA, V. F. Relação entre os setores de atividades econômicas e a oferta de vagas e cursos das principais modalidades de engenharia no Brasil. In: CONGRESSO BRASILEIRO DE EDUCAÇÃO EM ENGENHARIA. Anais [...]. Brasília: ABENGE, 2012.

CROCCO, M.; NOGUEIRA, M.; ANDRADE, C. O estudo do gap regional de crédito e seus determinantes sob uma ótica pós-keynesiana. Economia, Brasília, v. 12, p. 281-307, 2011.

DONI, Marcelo Viana. Análise de cluster: métodos hierárquicos e de particionamento. Universidade Presbiteriana Mackenzie, São Paulo, 2004.

DOW, S. C.; FUENTES, C. J. R. Um "survey" da literatura de finanças regionais. Autêntica, p. 39-75. Belo Horizonte, 2006.

ESTEBAN, P. P. C. El dinero y la liquidez. Ensayos sobre Política Económica, v. 32, n. 74, p. 36-51, 2014. https://doi.org/10.1016/S0120-4483(14)70026-0

FREITAS, A. P. G. de; PAULA, L. F. R. de. Concentração Regional do Crédito e Consolidação Bancária no Brasil: Uma Análise Pós-Real. Economia, v. 11, n. 1, p.97-123. Brasília, 2010.

GAMA, F. J. C.; BASTOS, S. Q. A.; HERMETO, A. M.; Moeda e crescimento: Uma análise para os municípios brasileiros (2000 a 2010). Nova Economia, v. 26, n. 2, p. 515-551. UFJF, 2016. https://doi.org/10.1590/0103-6351/3624

KEYNES, J. M. The general theory of employment interest and money. New York: Harcourt, 1964.

LOPEZ, J. DO C.; ROSSETTI, J. P. Economia Monetária. 7. ed. Atlas. São Paulo, 1998.

MISSIO, F. J.; JAYME Jr., F. G.; HERMETO, A. M. Desenvolvimento financeiro e crescimento econômico no Brasil (1995-2004). Economia \& Tecnologia (UFPR), v. 20, p. 65-74, 2010. https://doi.org/10.5380/ret.v6i1.27021

NAKAMURA, W. T. Decisão de investimento e a preferência pela liquidez no brasil. SIMPEP, 11., 2004. Anais [...]. p. 9. São Paulo, 2004.

NOGUEIRA, M.; CROCCO, M.; SANTOS, F. Sistema financeiro e atuação dos bancos públicos no desenvolvimento regional no Brasil. Bancos públicos e desenvolvimento. Ipea, p.151-177. Rio de Janeiro, 2010. 
RIBEIRO, A. das C.; MAROUVO, C. de C. O papel da moeda na dinâmica econômica da Baixada Fluminense - RJ. Redes: Revista do Desenvolvimento Regional, v. 21, n. 2, p.267-283. Santa Cruz do Sul, 2016. https://doi.org/10.17058/redes.v21i2.5574

SCHERMA, R. A.; KAHIL, S. P. Densidades do sistema financeiro: uso corporativo e desigualdades regionais do território brasileiro. Sociedade \& Natureza, v. 23, n. 1, p.105113. Uberlândia, 2011. https://doi.org/10.1590/S1982-45132011000100009

SIMÕES, R.; FURTADO, M. Estrutura agropecuária e rede urbana: Vale do Jequitinhonha/ Minas Gerais. In: Seminário sobre economia mineira. UFMG, 2006.

TOBIN, J. Liquidity preference as behavior towards risk. Review of Economics Studies, 1958. https://doi.org/10.2307/2296205

VERCELLI, A. Preferência pela liquidez e valor de opção. Economia e Sociedade, v. 8, n. 1, p. 21-40, 2016.

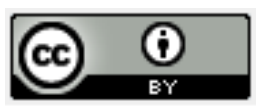

Artigo recebido em: 07/05/2018 e aceito para publicação em: 16/08/2019

DOI: http://dx.doi.org/10.14488/1676-1901.v19i3.3247 